\title{
Nickel in Nitrogen-Doped Graphene Nanotube as Efficient Electrocatalyst For Water Splitting
}

\author{
Bidushi Sarkar $^{1, \text { a) }}$ and Karuna Kar Nanda ${ }^{1}$ \\ ${ }^{1}$ Materials Research Centre, Indian Institute of Science, Bangalore-560012, India \\ a)bidushis@iisc.ac.in
}

\begin{abstract}
Designing an efficient bifunctional electrocatalyst for kinetically sluggish hydrogen evolution reaction (HER) and oxygen evolution reaction (OER) is a necessity for energy efficient water splitting. In this regard, we report facile synthesis of a phase pure face centered cubic (FCC) nickel electrocatalyst in nitrogen doped graphene nanotube (NGT) of diameter $\sim 100 \mathrm{~nm}$. The single step in-situ synthesis of Ni-NGT synthesized by pyrolysis is cost effective and the bifunctional catalytic activity that can compete with the state-of-the-art $\mathrm{Pt}-\mathrm{C}$ and $\mathrm{RuO}_{2}$ catalyst for HER and OER, respectively. The enhanced catalytic activity can be attributed to the synergistic effect of Ni active centers, defect sites due to N-doping and the conducting NGT support.
\end{abstract}

\section{INTRODUCTION}

Sustainable energy alternatives like hydrogen energy have gained significant attention due to the rapid demand for energy and depletion of fossil fuels [1,2]. Hydrogen has a zero net carbon fuel cycle and produces only water as by-product on combustion, however, the production of hydrogen is still challenging. In this regard, electrocatalytic water splitting which involves hydrogen evolution reaction (HER) at cathode and oxygen evolution reaction (OER) at anode is a green method to produce hydrogen. The energy required to drive the system can be derived from renewable resources like solar energy and this is an efficient way to store the intermittent solar energy into chemical energy in form of hydrogen. Both HER and OER are sluggish and require a catalyst to drive the reaction at an energy efficient mode [3, 4]. Currently, Pt-C and $\mathrm{RuO}_{2}$ are considered as the state-of-the-art catalyst for HER and OER, respectively [5-7]. But the high cost and long-term instability demands design of an efficient and affordable catalyst.

Here, we report a Ni electrocatalyst encapsulated in nitrogen doped graphene nanotube (NGT, diameter 100 $\mathrm{nm}$ ) for efficient bifunctional catalysis. The Ni catalyst obtained in-situ by a single step pyrolysis is affordable and competes with the state-of-the-art catalysts in terms of catalytic activity. The NGT support enhances conductivity, stability in harsh environment and prevents coagulation of Ni nanoparticles. The N-doping act as defect active site and further enhances the catalytic activity. The Ni nanoparticles at the tip of NGT act as the active sites facilitating electron transfer during the catalytic activity.

\section{EXPERIMENTAL SECTION}

The synthesis of Ni metal in NGT was carried out by taking dicyandiamide $\left(\mathrm{C}_{2} \mathrm{H}_{4} \mathrm{~N}_{4}, 1 \mathrm{~g}\right)$ as a source of carbon as well as nitrogen and nickel nitrate hexahydrate $\left(\mathrm{Ni}\left(\mathrm{NO}_{3}\right)_{2} \cdot 6 \mathrm{H}_{2} \mathrm{O}, 100 \mathrm{mg}\right)$ as a source of $\mathrm{Ni} .10 \mathrm{~mL}$ of ethanol was added followed by sonication for $30 \mathrm{~min}$. The solution was dried at $70{ }^{\circ} \mathrm{C}$ and transferred into in a closed quartz tube which was pyrolyzed at $900{ }^{\circ} \mathrm{C}$ for $2 \mathrm{~h}$. The as obtained sample was named as Ni-NGT. 
The sample was characterized by X-ray diffraction (XRD) using PANalytical X-ray diffractometer $\left(\mathrm{Cu} \mathrm{K}_{\alpha}\right.$ radiation, $1.54 \AA$ ). Raman spectra was recorded on a WITec system (excitation wavelength, $532 \mathrm{~nm}$ ). The scanning electron microscopy (SEM) was done using a FESEM FEI Inspect 50 and the transmission electron microscopy (TEM) was carried out using JEOL JEM-2100F (accelerating voltage, $200 \mathrm{kV}$ ).

The electrocatalytic activity was tested on three electrodes set up using a CHI 750E workstation with a rotating disc electrode, i.e., commercial glassy carbon electrode (GCE, $0.07 \mathrm{~cm}^{2}$ area), a silver/silver chloride electrode and Pt wire electrode as working, reference and counter electrodes, respectively. The catalyst ink was prepared by taking $2 \mathrm{mg}$ of the sample and adding $200 \mu \mathrm{L}$ of ethanol followed by $20 \mu \mathrm{L}$ of $5 \mathrm{wt} \%$ Nafion solution and sonicating for $30 \mathrm{~min} .5 \mu \mathrm{L}$ of the catalyst ink was drop-casted onto the GCE and dried at $70{ }^{\circ} \mathrm{C}$ (catalyst loading, $0.64 \mathrm{mg} / \mathrm{cm}^{2}$ ). The potential measured was converted versus reversible hydrogen electrode (RHE) using the equation, $\mathrm{E}_{\mathrm{vsRHE}}=$ $\mathrm{E}_{\mathrm{vsAg} / \mathrm{AgCl}}+\mathrm{E}_{\mathrm{Ag} / \mathrm{AgCl}^{\circ}}+0.059 \mathrm{pH}\left(\mathrm{E}_{\mathrm{vsAg} / \mathrm{AgCl}}\right.$, experimental potential measured against $\mathrm{Ag} / \mathrm{AgCl}$ reference electrode, $\mathrm{E}_{\mathrm{Ag} / \mathrm{AgCl}}$, standard potential of $\left.\mathrm{Ag} / \mathrm{AgCl}\right)$. The catalytic activity was studied in alkaline medium $(1 \mathrm{M} \mathrm{KOH}$ solution, $\mathrm{pH}=14)$.

\section{RESULTS AND DISCUSSION}

The XRD pattern shown in Fig. 1a depicts the successful synthesis of phase pure face centered cubic (FCC) Ni in Ni-NGT. A broad peak at $\sim 26^{\circ}$ correspond to the (002) plane of the graphitic carbon. The Raman spectrum of NiNGT is shown in Fig. $1 \mathrm{~b}$ that depicts the $\mathrm{D}$ band $\left(1365 \mathrm{~cm}^{-1}\right)$ and $\mathrm{G}$ band $\left(1597 \mathrm{~cm}^{-1}\right)$ corresponding to the disordered or defected carbon due to the N-doping, and characteristic of $\mathrm{sp}^{2}$ hybrid carbon, respectively. The $\mathrm{I}_{\mathrm{D}} / \mathrm{I}_{\mathrm{G}}$ band intensity ratio is $\sim 1$ suggesting a large amount of $\mathrm{N}$ doping in the carbon. A broad $2 \mathrm{D}$ band is seen at 2850 $\mathrm{cm}^{-1}$ depicting the presence of a few layers of graphene.
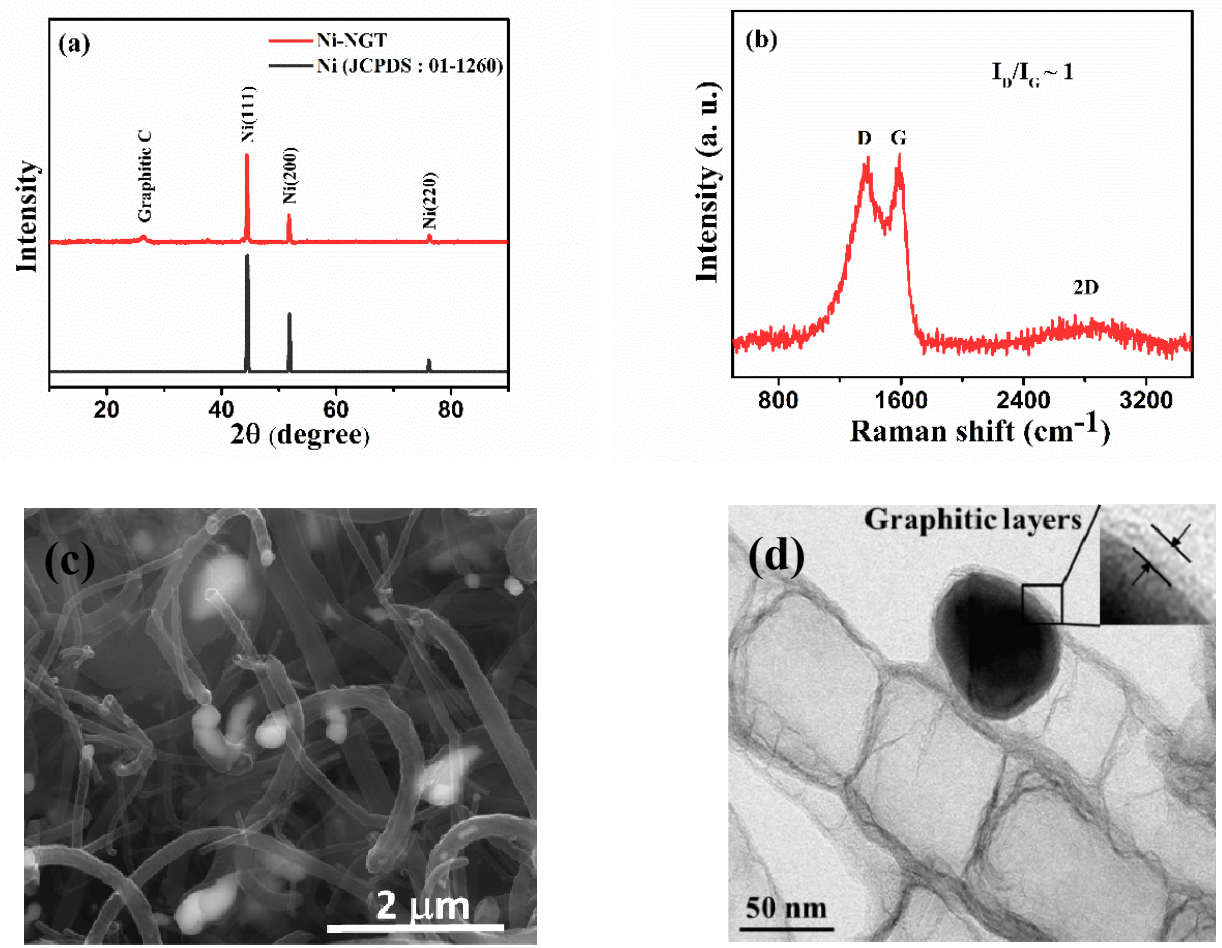

FIGURE 1. (a) XRD pattern, (b) Raman spectrum, (c) SEM image, and (d) TEM image of Ni-NGT. 
The morphology of Ni-NGT was studied using SEM and TEM. The SEM image shown in Fig. 2a depicts the graphene nanotube structure with the $\mathrm{Ni}$ at the tip of the tube that is suggestive of tip growth mechanism for NGT. The TEM image as shown in Fig. $2 \mathrm{~b}$ also confirms the NGT structure with a tube diameter of $\sim 100 \mathrm{~nm}$ and the Ni nanoparticle encapsulated in 4-5 graphitic layers at the tip. The bamboo-like structure is typical of $\mathrm{N}$ doping. A polymeric carbon nitride is formed from dicyandiamide which decomposes with release of a large amount of cyano fragments $\left(\mathrm{C}_{2} \mathrm{~N}_{2}{ }^{+}, \mathrm{C}_{3} \mathrm{~N}_{2}{ }^{+}, \mathrm{C}_{3} \mathrm{~N}_{3}{ }^{+}\right)$, which provides both a $\mathrm{C}$ and $\mathrm{N}$ source for the formation of NGT at temperature above $700{ }^{\circ} \mathrm{C}$. The $\mathrm{Ni}^{2+}$ ions are reduced to metallic $\mathrm{Ni}$ in the reducing environment which catalyzes the growth of NGT.

\section{ELECTROCATALYTIC ACTIVITY}
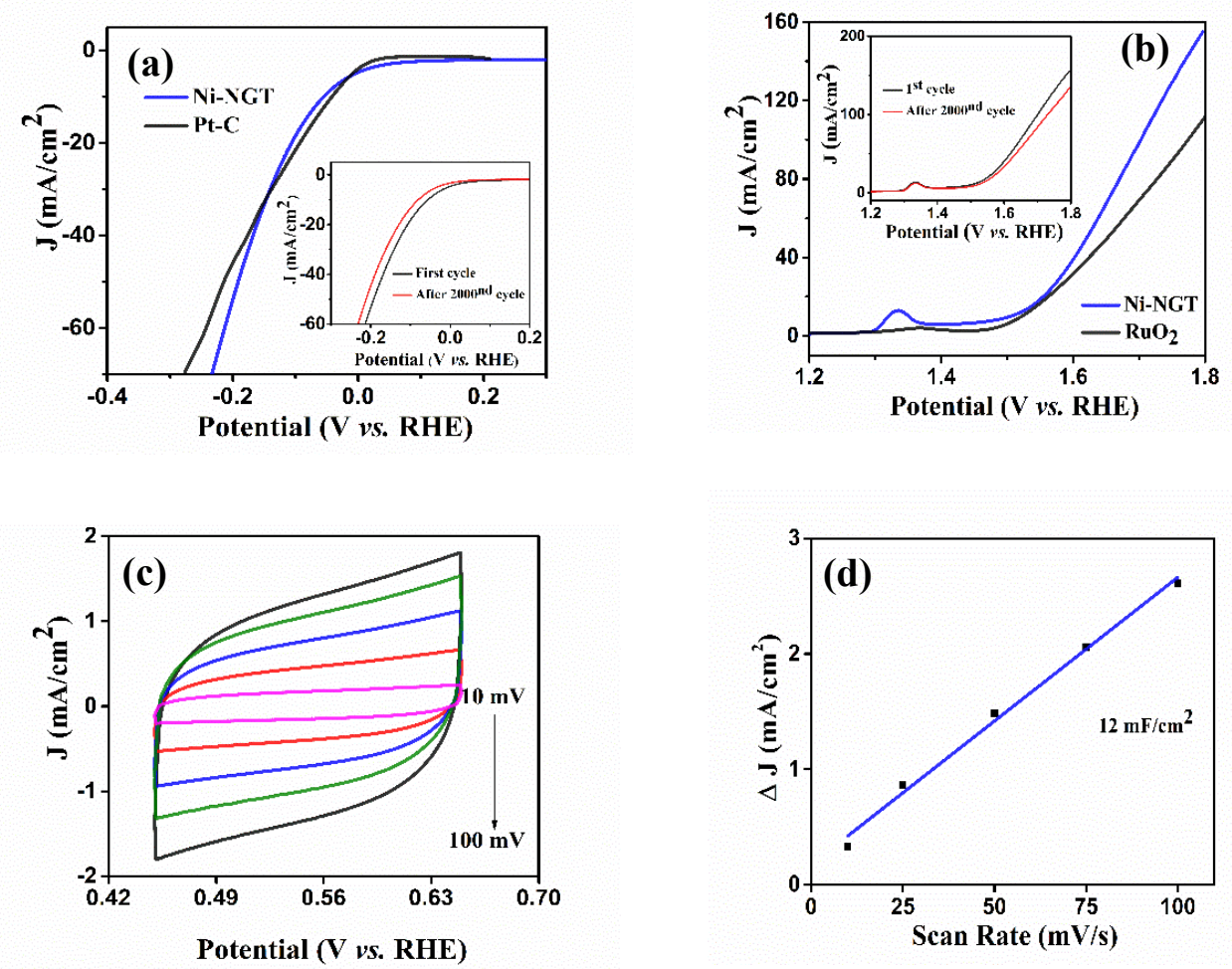

FIGURE 2. (a) LSV polarization curve for (a) HER at scan rate of $10 \mathrm{mV} / \mathrm{s}$. Inset: ADT at scan rate of $100 \mathrm{mV} / \mathrm{s}$. (b) OER at scan rate of $10 \mathrm{mV} / \mathrm{s}$. Inset: ADT at scan rate of $100 \mathrm{mV} / \mathrm{s}$. (c) $\mathrm{CV}$ at different scan rates in the faradaic silent region. and (d) $\mathrm{C}_{\mathrm{dl}}$ curve.

The HER activity was studied in $1 \mathrm{M} \mathrm{KOH}$ at a scan rate of $10 \mathrm{mV} / \mathrm{s}$ and rotation speed of $1600 \mathrm{rpm}$. The linear sweep voltammetry (LSV) curve shown in Fig. 2a depicts that Ni-NGT competes well with Pt-C with an overpotential to reach current density of $10 \mathrm{~mA} / \mathrm{cm}^{2}$ of 52 and $44 \mathrm{mV}$, respectively. The inset shows the LSV curve of accelerated durability test (ADT) and the stability after 2000nd cycles is commendable. The OER LSV curve is shown in Fig. $2 \mathrm{~b}$ which shows better catalytic activity than $\mathrm{RuO}_{2}$. The overpotential required to reach current density of $10 \mathrm{~mA} / \mathrm{cm}^{2}$ is 270 and $290 \mathrm{mV}$ for Ni-NGT and $\mathrm{RuO}_{2}$, respectively. Inset shows the ADT with a decrease of only $15 \%$ in current after $2000^{\text {nd }}$ cycles. The oxidation peak at around $1.36 \mathrm{~V}$ in the LSV curve of Ni-NGT is characteristic of the oxidation of $\mathrm{Ni}^{2+} / \mathrm{Ni}^{3+}$ seen in many nickel based electrocatalysts. Figure $2 \mathrm{c}$ shows the cyclic 
voltammetry $(\mathrm{CV})$ curves at different scan rates at faradaically silent region. The linear relationship between $\Delta \mathrm{J}$ and the different scan rates is shown in Fig. $2 \mathrm{~d}$. The double-layer capacitance, $\mathrm{C}_{\mathrm{dl}}$ is half the slope of the curve and is directly proportional to the electrochemically active surface area (ECSA). The $\mathrm{C}_{\mathrm{dl}}$ calculated for Ni-NGT is 12 $\mathrm{mF} / \mathrm{cm}^{2}$ and directly relates to the ECSA.

\section{CONCLUSION}

The successful in-situ synthesis of Ni electrocatalyst encapsulated in N-doped graphene nanotube is reported and subjected to bifunctional HER and OER activity. The Ni active sites facilitate the electron transfer during the catalytic activity, and the N-doping creates defect sites which further enhances the activity. Further, the NGT prevents Ni nanoparticle agglomeration, enhances the conductivity and provides long term durability.

\section{ACKNOWLEDGMENTS}

B. S. and K. K. N. thank the Department of Science and Technology (DST), India for financially supporting the proposal. This work is an outcome of the proposal.

\section{REFERENCES}

1. C. Wei, R. R. Rao, J. Peng, B. Huang, I. E. L. Stephens, M. Risch, Z. J. Xu and Y. Shao-Horn, Adv. Mater. 31, 1806296 (2019).

2. M. T. M. Koper, Nat. Chem. 5, 255-256, (2013).

3. J. Shan, T. Ling, K. Davey, Y. Zheng and S. -Z. Qiao, Adv. Mater. 31, 1900510 (2019).

4. B. Sarkar, B. K. Barman and K. K. Nanda, ACS Appl. Energy Mater. 1, 1116-1126 (2018).

5. M. Zhou, S. Bao and A. J. Bard, J. Am. Chem. Soc. 141, 7327-7332, (2019).

6. B. S. Yeo, Nature Catalysis 2, 284-285 (2019).

7. S. Laha, Y. Lee, F. Podjaski, D. Weber, V. Duppel, L. M. Schoop, F. Pielnhofer, C. Scheurer, K. Müller, U. Starke, K. Reuter and B. V. Lotsch, Adv. Energy Mater. 9, 1803795 (2019). 